The impact of illness-related shame on psychological health and social relationships: Testing a mediational model in students with chronic illness

\author{
Inês A. Trindade, MSc, PhD student $1 *$ \\ Joana Duarte, $\mathrm{PhD}^{1}$ \\ Cláudia Ferreira, $\mathrm{PhD}^{1}$ \\ Mariana Coutinho, $\mathrm{MSc}^{2}$ \\ José Pinto-Gouveia, $\mathrm{MD}, \mathrm{PhD}^{1}$ \\ ${ }^{1}$ CINEICC - Cognitive-Behavioural Research Centre \\ Faculty of Psychology and Education Sciences \\ University of Coimbra, Portugal \\ ${ }^{2}$ University of Coimbra, Portugal
}

*Corresponding author: Inês A. Trindade, Faculdade de Psicologia e de Ciências da Educação da Universidade de Coimbra, Rua do Colégio Novo, 3000-115 Coimbra, Portugal. Email: ines.almeidatrindade@gmail.com

The final publication is available at Wiley via

http://onlinelibrary.wiley.com/doi/10.1002/cpp.2175/full 


\title{
The impact of illness-related shame on psychological health and social relationships: Testing a mediational model in students with chronic illness
}

\begin{abstract}
This study explores the impact of illness-related shame on the quality of social relationships and psychological health in chronic patients. We aimed to examine the roles of fear of receiving compassion from others and experiential avoidance as potential mediators of this relationship. Although some studies have demonstrated the negative impact of chronic illness-related shame on psychological functioning, the mechanisms that may underlie this link remain understudied.
\end{abstract}

The sample was comprised by 115 college students, which had been diagnosed with at least 1 chronic illness. Participants completed self-report measures on an online platform. This study's design was cross-sectional. A path analysis was conducted using structural equation modelling. Results showed that the impact of illness-related shame on both psychological health $\left(R^{2}=.45\right)$ and the quality of social relationships $\left(R^{2}=.33\right)$ was fully accounted by fear of compassion from others and experiential avoidance. This model revealed an excellent fit. Fear of receiving compassion from others was the main mediator of the illness-related shame link with the quality of social relationships $(\beta=-.22)$. The main mediator of the association between shame-related chronic illness and psychological health was experiential avoidance $(\beta=-.21)$.

This study shed light on possible psychological mechanisms linking feelings of shame associated with having a chronic condition and impaired social relationships and mental health. On one hand, resisting feelings of compassion and care from others and, on the other hand, avoiding difficult internal experiences and situations that might trigger 
them seem to underlie the impact of shame on psychological and social functioning in chronic patients.

Keywords: chronic illness, college students, experiential avoidance, fear of compassion, illness shame, psychosocial functioning.

\section{Key Practitioner Message}

- The impact of illness-related shame on psychological health and the quality of social relationships were fully explained by fear of compassion and experiential avoidance, in students with chronic illness.

- Resisting feelings of compassion and care from others and avoiding difficult internal experiences seem to underlie the impact of shame on psychological and social functioning in chronic patients. 


\section{Introduction}

Extensive literature has demonstrated that chronic illness has a significant impact on patients' psychological, social, and physical functioning (e.g., Alonso et al., 2004; Keles, Ekici, Ekici, Bulcun, \& Altinkaya, 2007). Chronic patients usually present lower levels of perceived independence from others, decreased quality in interpersonal relationships, feelings of not being understood by others, feelings of isolation and helplessness, as well as feelings of being a burden to others (Casati, Toner, de Rooy, Drossman, \& Maunder, 2000; Taylor, 2006). In particular, college students with chronic illness have greater absenteeism and more difficulties in graduating when compared to healthy peers (Maslow, Haydon, McRee, Ford, \& Halpern, 2011). Moreover, isolation and loneliness are especially relevant in youth with chronic illness; these constructs may be important mediators of the link between health behaviours and depression (Bishop, 2005). Additionally, chronic patients can be more prone to experience shame feelings regarding their illness and symptomatology (e.g., Casati et al., 2000; Kellett \& Gilbert, 2001).

Shame is a self-conscious painful emotion that functions as a warning signal for the risk of being excluded or rejected by one's social group (Gilbert, 1998). In this way, shame is trigged by situations where one feels that he or she is different, unattractive, inferior, or inadequate. These feelings usually arise from the perception that one has personal characteristics (e.g., personality traits, an illness, and physical appearance) or from having behaviours that may be evaluated by others as inappropriate and result in some form of criticism or rejection (Gilbert, 1998; Tangney \& Fischer, 1995). In general, high levels of shame are linked with lower quality of life scores and psychopathology (e.g., Kim, Thibodeau, \& Jorgensen, 2011; Tangney \& Dearing, 2002). However, few 
studies to date have explored the impact of chronic illness-related shame on patients' wellbeing (Trindade, Ferreira, \& Pinto-Gouveia, 2017a, 2017b).

Importantly, literature has suggested that the impact of painful emotions on wellbeing may be more determined by one's ability to adaptively regulate those experiences than by the experience itself (e.g., Gross, 1998; Segal, Williams, \& Teasdale, 2002). On one hand, one may choose to cope with painful experiences in an adaptive way (e.g., acceptance and decentering), or, on the other hand, one may try to control, suppress, or inhibit internal experiences in an effort to decrease their intensity, content, or duration (Hayes, Strosahl, \& Wilson, 2012). This maladaptive coping style has been referred to as experiential avoidance and is associated with a wide range of psychological difficulties (see Hayes, Wilson, Gifford, Follette, \& Strosahl, 1996). Indeed, although experiential avoidance may provide short-term relief of difficult feelings, in the long-term, it may intensify those feelings (Chawla \& Ostafin, 2007; Ruiz, 2010). Furthermore, experiential avoidance strategies are usually inflexible, behaviourally restrictive, and hardly meaningful. For chronic patients, experiential avoidance may be particularly relevant as it may have direct impact on health behaviours and disease management (e.g., comply with doctors' recommendations and treatment, undergoing medical exams; Hadlandsmyth, White, Nesin, \& Greco, 2013). Furthermore, experiential avoidance may interfere with the self-disclosure of the chronic illness that may then have an impact not only on psychological wellbeing but also on the quality of social relationships (e.g., Sprecher \& Hendrick, 2004). In line with these studies, recent data have shown that experiential avoidance is linked with illness-related shame and low quality of life in samples of inflammatory bowel disease patients (Trindade et al., 2017b).

Experiential avoidance may occur in the context of experiences that most people would find unpleasant but may also take place to avoid experiences generally perceived 
as positive (Bond et al., 2011). In this context, some people may avoid affiliative-related feelings based on negative perceptions about being the recipient of compassion and care from others (fear of becoming dependent, fear of being seen as weak and vulnerable, fear

of being taken advantage of, and fear of intimacy). Recently, the construct of fear of compassion has been proposed to describe these feelings of discomfort, difficulty, or resistance to affiliative-based emotions, other- or self-directed (Gilbert, McEwan, Matos, \& Rivis, 2011). Fear of being a recipient of compassion from others has in fact been linked to experiential avoidance (Duarte \& Pinto-Gouveia, 2017) and to psychological difficulties, such as depression, anxiety, stress, and self-criticism in students (Gilbert et al., 2011; Gilbert et al., 2012) and in depressed patients (Gilbert, McEwan, Catarino, Baião, \& Palmeira, 2014).

Fear of receiving compassion from others may be particularly important for patients with chronic illnesses as it may prevent one from receiving the adequate amount of social support and from maintaining healthy interpersonal relationships. In this way, it seems particularly important to explore the role of fear of receiving compassion and experiential avoidance on the impact of shame on psychological adjustment and the quality of social relationships in students with chronic patients. This is the main aim of the current study, and it is expected that these processes will mediate the relationship between chronic illness-related shame and these outcomes.

\section{Material and methods}

\section{Participants}

The sample was comprised by 115 college students (19 males and 96 females), which had been diagnosed with at least one chronic illness. Participants presented a mean 
age of 24.27 (standard deviation $[S D]=4.54)$ and a mean of $15.08(S D=1.81)$ completed years of education. The majority of participants were enrolled in Bachelor, Master, or PhD studies in Psychology, Education Sciences, Engineering, Tourism, Biology, Geology, and Nursing. The most reported diagnoses of chronic health conditions were asthma (22.6\%), Crohn's disease (9.6\%), and psoriasis (9.6\%). A comprehensive list of participants' chronic illnesses is presented in Table 1. Eighteen participants (15\%) had been diagnosed with more than one chronic health condition. Time since diagnosis ranged from 1 month to 24 years (mean $=9.20 ; S D=7.42$ years). Regarding hospital admissions, 42 participants $(36.5 \%)$ reported having been hospitalized in the past.

Please insert Table 1 around here

\section{Measures}

Participants reported demographic (age, completed years of education, and marital status) and medical data and completed the Portuguese validated versions of the following measures on a secure online platform:

Chronic illness-related shame scale (CISS; Trindade et al., 2017a). The CISS is a 7-item measure of chronic illness-related shame (e.g., "I'm ashamed of talking with others about my illness or symptoms." "I feel that others may evaluate me negatively (or criticize me) due to my illness and symptoms."). Each item is rated on a 5-point Likert (0: Never True; 4: Always True). Higher scores reveal higher levels of shame specifically associated with the experience of having an illness and/or its symptomatology. The scale has presented a Cronbach's alpha of .91 in its original study, which was conducted with Portuguese chronic patients. 
Fears of compassion scales (FCS; Gilbert et al., 2011; Simões \& Pinto-Gouveia, 2012). This scale is composed of three subscales: (a) fear of compassion for self (that assesses the fear and resistance of demonstrating affiliative emotions and compassion for the self); (b) fear of compassion from others (that measures fears of receiving kindness and compassion from others); and (c) fear of compassion for others (that assesses fear of expressing sensitivity or compassion for others). In this study, only the second subscale was used (fear of compassion from others). This subscale presents 13 items rated on a 5point Likert scale $(0=$ Don't agree at all to $4=$ Completely agree $)$ and has presented adequate psychometric properties in its original $(\alpha=.85)$ and Portuguese validation studies $(\alpha=.91)$.

Acceptance and Action Questionnaire-II (AAQ-II; Bond et al., 2011; PintoGouveia, Gregório, Dinis, \& Xavier, 2012). The AAQ-I is a 10-item measure with a 7point scale (1: Never true; 7:Always True) that aims to assess experiential avoidance. Higher scores indicate higher levels of this emotion regulation process. The instrument has presented good internal consistencies in the original study (with a mean $\alpha$ of .84 across different six samples) and the Portuguese validation study $(\alpha=.90)$.

World Health Organization Brief Quality of Life Assessment Scale (WHOQOLBREF; Canavarro et al., 2009; The WHOQOL Group, 1998). The WHOQOL-BREF is 16-item measure of subjective quality of life with four factors: physical health, environmental health, psychological health, and social relationships. In this study, in accordance with its aims, only two domains were used (psychological health and social relationships). Items are rated on a 5-point Likert scale, with higher scores indicating higher levels of perceived quality of life. The instrument showed adequate psychometric features in the original ( $\alpha$ s between .66 and .84) and Portuguese ( $\alpha$ s between .67 and .87) validation studies. 
These measures demonstrated adequate to excellent internal reliabilities (P. Kline, 2000) in this study (Table 2).

\section{Procedures}

This study has respected all ethical principles of research in human beings. The Ethic Committees of the involved institutions approved the research. Participants were invited to participate in the study through online advertisements, shared by the research team on a social network with the help of several Patient Associations. Potential participants were informed about the study's design and inclusion criteria, the voluntary and confidential nature of their participation, and the estimated time of completion of the self-report questionnaires. All participants signed a written informed consent.

Inclusion criteria for participation in this study were the following: (a) 18 years old or older; (b) enrolment in an undergraduate or graduate course; (c) native speaker of Portuguese; and (d) absence of a psychiatric condition and difficulty in completing questionnaires.

\section{Statistical Analysis}

Correlation analyses (Cohen, Cohen, West, \& Aiken, 2003) were conducted using IBM SPSS Statistics 23.0 (SPSS IBM; Chicago, IL, USA), and path analyses were performed using AMOS software 23.0 (Arbuckle, 2014).

A path analysis tested a theoretical model that analysed whether fear of compassion from others and experiential avoidance would mediate the relationship between chronic illness-related shame and psychological health and social relationships. This analysis was performed using maximum likelihood as estimation method. Path analysis is a type of structural equation modelling that analyses structural associations 
and the significance of direct and indirect paths (e.g., Schumacker \& Lomax, 2004). This analysis was conducted using the bootstrap procedure (with 5,000 samples) to create $95 \%$ bias-corrected confidence intervals around the standardized estimates of total, direct, and indirect effects. If the interval between the lower and the upper bound of the $95 \%$ biascorrected confidence interval does not include zero, the effects are considered statistically significant (R. B. Kline, 2005). The adequacy of the tested model to the data was analysed recurring to the chi-square goodness-of-fit (that reveals a good fit when nonsignificant; Hair, Anderson, Tatham, \& Black, 1998), the comparative fit index and the Tucker and Lewis index that reveal a good model fit when values are superior to .95 (Hooper, Coughlan, \& Mullen, 2008; Hu \& Bentler, 1999), the root mean squared error of approximation (which reveals a good adjustment when values are inferior to .06; $\mathrm{Hu} \&$ Bentler, 1999), and the standardized root mean squared residual that indicates a good model fit when inferior to .08 (Hu \& Bentler, 1999).

Preliminary data analyses were performed before the conduction of the other statistical analyses. An analysis of skewness and kurtosis' values demonstrated that the variables did not present a considerable bias to normal distribution $(\mathrm{Sk}=|0.25-1.06| ; \mathrm{Ku}$ $=|0.08-0.54|)$. The assumption of normality was confirmed through the visual inspection of the distributions. No multivariate outliers were identified through Mahalanobis distance squared analysis (R. B. Kline, 2005).

\section{Results}

\section{Correlations}

Results from the correlation analysis (Table 2) demonstrated that illness-related shame was positively linked to fear of compassion from others and experiential 
avoidance, with high and moderate magnitudes, respectively. Illness-related shame was negatively and moderately associated with the quality of social relationships and psychological health. Fear of receiving compassion from others was positively and highly related to experiential avoidance, and both of these processes presented negative and high associations with the quality of social relationships and psychological health.

Please insert Table 2 around here

\section{Path analyses}

The model was firstly explored through a fully saturated model to analyse whether fear of compassion from others and experiential avoidance would be mediators of the relationship of illness-related shame with the quality of social relationships and psychological health. This model had 24 parameters and presented the following nonsignificant paths that were progressively removed: the effect of illness-related shame on psychological health $\left(b_{\text {CISS }}=-0.15\right.$; standard error $\left.[S E]=0.20 ; Z=-0.75 ; p=.456\right)$ and the effect of illness-related shame on the quality of social relationships $\left(b_{\mathrm{CISS}}=-0.23\right.$; $S E=0.29 ; Z=-0.78 ; p=.433)$. After the removal of these paths, the model was retested.

The final nested model (Figure1) presented an excellent adjustment to the data, with a nonsignificant chi-square of $\chi 2(2)=1.16, p=.582$, and the following goodnessof-fit indices: comparative fit index $=1.00$; Tucker and Lewis index $=1.02$; root mean squared error of approximation $=0.00$ (confidence interval $[\mathrm{CI}]$ from 0.00 to $0.16 ; p=$ .643 ); and standardized root mean squared residual $=0.02$. The model accounted for $29 \%$ of the variance of fear of compassion from others, $17 \%$ of the variance of experiential avoidance, $33 \%$ of the variance of the quality of social relationships, and $45 \%$ of the variance of psychological health. 
Please insert Figure 1 around here

Illness-related shame presented a direct effect of 0.54 on fear of compassion from others $\left(\mathrm{b}_{\mathrm{CISS}}=0.91 ; S E=0.13 ; Z=6.84 ; p<.001\right)$ and of 0.4 on experiential avoidance $\left(\mathrm{b}_{\text {CISS }}=0.55 ; S E=0.11 ; Z=4.90 ; p<.001\right)$. Fear of compassion from others in turn predicted the quality of social relationships and psychological health with direct effects of $-0.40\left(b_{\mathrm{FCS}}=-0.79 ; S E=0.18 ; Z=-4.53 ; p<.001\right)$ and $-0.25\left(b_{\mathrm{FCS}}=-0.35 ; S E=\right.$ $0.11 ; Z=3.08 ; p=.002)$, respectively. Further, as expected, experiential avoidance had a direct effect of 0.51 on psychological health $\left(b_{\mathrm{AAQ}-\mathrm{II}}=-0.90 ; S E=0.14 ; Z=-6.24 ; p<\right.$ $.001)$ and of -0.26 on the quality of social relationships $\left(b_{\mathrm{AAQ}-\mathrm{II}}=-0.26 ; S E=0.22 ; Z=\right.$ $-2.89 ; p=.004)$.

The indirect effects of the model were also analysed. Illness-related shame presented an indirect effect of $-0.33(95 \% \mathrm{CI}=-0.47$ to $-0.20 ; p<.001)$ on the quality of social relationships and an indirect effect of $-0.35(95 \% \mathrm{CI}=-0.47$ to $-0.21 ; p<.001)$ on psychological health, which were totally mediated by fear of receiving compassion from others and experiential avoidance. The specific effects of the mediators were calculated, and it was revealed that $66.67 \%(\beta=-.22)$ of the indirect effect of illnessrelated shame on the quality of social relationships was carried by fear of compassion, whereas $60 \%(\beta=-.21)$ of the indirect effect of illness-related shame on psychological health was carried by experiential avoidance.

\section{Discussion}

The current study aimed to explore the impact of illness-related shame on the quality of social relationships and psychological health in chronic patients. Additionally, 
we aimed to examine the role of cognitive and emotional processes (fear of compassion from others and experiential avoidance) as potential mediators of this relationship. Although some studies have demonstrated the negative impact of chronic illness-related shame on psychological functioning and wellbeing (e.g., Trindade et al., 2017a, 2017b), the mechanisms that may underlie this link remain understudied.

Results showed that illness-related shame was negatively associated with the quality of social relationships and psychological health. This result is in line with an extensive literature that has documented the adverse effects of shame on psychological functioning (for a meta-analysis, see Kim et al., 2011). This finding suggests that individuals who have subjective feelings of inferiority, inadequacy, unattractiveness, and negative social comparisons (Gilbert, 1998) due to having a chronic disease also present more general psychological dysfunction and psychological symptoms. Further, because shame is a self-conscious emotion intrinsically linked to self-other relations, presenting a crucial role in social relating, the finding that this emotion was linked to decreased quality in social relationships was expected. The withdrawal/hide/conceal functions of the shame response (Gilbert, 1998) may lead to decreased engagement in significant and intimate interactions and thus to impaired interpersonal relationships.

Path analysis results revealed that these associations were mediated by fear of receiving compassion from others and experiential avoidance. Specifically, the impact of illness-related shame on both psychological health and the quality of social relationships was fully accounted by these two processes. Fear of receiving compassion from others was the main mediator of the illness-related shame link with the quality of social relationships. This result is in line with our hypothesis and suggests that shame related to a chronic illness may lead to the avoidance and resistance of feelings of compassion, care, and affiliation from other people. In turn, this resistance of receiving compassion from 
others may lead to feelings of isolation and lack of connectedness and social support, which may then have a negative impact on the quality of social relations. People with chronic illnesses may have misconceived or erroneous beliefs about receiving care and support from others that they may interpret as pity, being a burden to others, and being seen as dependable and vulnerable by others. These negative beliefs regarding compassion from others may then trigger avoidance of supportive social interactions and intimate relationships. In fact, experiential avoidance was positively linked with fear of compassion from others that gives some support to this idea (Duarte \& Pinto-Gouveia, 2017). Furthermore, fear of receiving compassion also mediated the relationship between illness-related shame and psychological health, which corroborates and adds to previous literature (Gilbert et al., Gouveia; Gilbert et al., 2012; Gilbert et al., 2014; Hermanto et al., 2016; Miron, Seligowski, Boykin, \& Orcutt, 2016).

Nonetheless, the main mediator of the association between shame-related chronic illness and psychological health was experiential avoidance. Experiencing strong painful shame feelings may lead to attempts at avoiding and controlling these difficult internal experiences, which may provide a relief in the short-term but has long-term paradoxical consequences such as rebound of emotion and thoughts (e.g., Cioffi \& Holloway, 1993; Gross \& Levenson, 1997; Wegner, Schneider, Carter, \& White, 1987). This, in turn, seems to decrease psychological functioning and health such as has been found in our study and previous literature (e.g., Costa \& Pinto-Gouveia, 2013; Hayes et al., 2004; Hayes et al., 1996; Trindade, Ferreira, \& Pinto- Gouveia, 2015). Interestingly, experiential avoidance was also a significant mediator of the link between illness-related shame and social relationships' quality, which may suggest that illness-related shame may prompt avoidance of interpersonal situations that may trigger negative evaluations and judgments by other people in an effort to avoid perceived social threats, exposure, and 
more shame feelings. In the long term, this process holds a cost to the quality of social interactions. Patients who have strong shame feelings about their chronic health conditions may adopt avoidance strategies as a way to down regulate these feelings, such as exposure to social situations in which one may perceive others as judgmental and selfdisclosure about one's condition and symptoms. These behaviours may consequently lead to impaired social interactions and, because they actually increase the initial feelings of shame, to increased psychological symptoms.

The cross-sectional nature of this study does not allow to establish causal directions between the variables. In fact, we hypothesize that all the studied processes and outcomes potentiate each other in a self-perpetuating negative cycle. For instance, the experience of shame feelings related to an illness may lead to attempts to control those feelings by avoiding social situations that leads to poor relationships that in turn may reinforce feelings of inferiority, inadequacy in a vicious cycle.

Future research should therefore attempt to explore these links using longitudinal designs. Other important limitations of this study were the use of a convenience sample of college students that limits the generalizability of the findings to other groups, the small sample size, and the unequal ratio of female to male participants. Thus, these results should be replicated using more homogeneous, larger, and probabilistic samples. Also, these results should be explored in samples with specific chronic conditions due to possible specificities of particular illnesses. Further, the use of self-report measures is another important limitation given that the effects of bias associated with this methodology (e.g., response bias and social desirability) and of shared method variance cannot be ruled out. Thus, future studies should use other methods to explore this data such as physiological indicators and third person reports. 
To sum up, this study shed some light on possible psychological mechanisms linking feelings of shame associated with having a chronic condition and impaired social relationships and mental health. In fact, on one hand, resisting feelings of compassion and care from others and, on the other hand, avoiding difficult internal experiences and situations that might trigger them seem to be the underlying mechanisms of the impact of shame on psychological and social functioning in chronic patients. By promoting openness and availability to compassion (from the self and from and to others) and to experience internal experiences (even when painful), compassion and acceptance-based psychotherapies may respectively be useful to improve psychosocial functioning in patients with chronic illnesses.

\section{Acknowledgments}

This research has been supported by the first author (Inês A Trindade)'s PhD Grant (SFRH/BD/101906/2014) sponsored by FCT (Portuguese Foundation for Science and Technology).

\section{References}

Alonso, J., Ferrer, M., Gandek, B., Ware, J. E., Aaronson, N. K., Mosconi, P., ... Leplège, A. (2004). Health-related quality of life associated with chronic conditions in eight countries: Results from the International Quality of Life Assessment (IQOLA) Project. Quality of Life Research: an International Journal of Quality of Life Aspects of Treatment, Care and Rehabilitation, 13(2), 283-298. https://doi.org/10.1023/B:QURE.0000018472.46236.05.

Arbuckle, J. L. (2014). Amos 23.0 User's Guide. Chicago: IBM SPSS. 
Bishop, M. (2005). Quality of life and psychosocial adaptation to chronic illness and disability: Preliminary analysis of a conceptual and theoretical synthesis. Rehabilitation Counseling Bulletin, 48(4), 219-231. https://doi.org/10.1177/00343552050480040301.

Bond, F. W., Hayes, S. C., Baer, R. A., Carpenter, K. M., Guenole, N., Orcutt, H. K., ... Zettle, R. D. (2011). Preliminary psychometric properties of the Acceptance and Action Questionnaire-II: A revised measure of psychological inflexibility and experiential avoidance. Behavior Therapy, 42(4), 676-688. https://doi.org/10.1016/j.beth.2011.03.007.

Canavarro, M. C., Serra, A. V., Simões, M. R., Rijo, D., Pereira, M., Gameiro, S., ... Paredes, T. (2009). Development and psychometric properties of the world health organization quality of life assessment instrument (WHOQOL-100) in Portugal. International Journal of Behavioral Medicine, 16(2), 116-124. https://doi.org/10.1007/s12529-008-9024-2.

Casati, J., Toner, B. B., de Rooy, E. C., Drossman, D. A., \& Maunder, R. G. (2000). Concerns of patients with inflammatory bowel disease: A review of emerging themes. Digestive Diseases and Sciences, 45, 26-31. https://doi.org/10.1023/A:1005492806777.

Chawla, N., \& Ostafin, B. (2007). Experiential avoidance as a functional dimensional approach to psychopathology: An empirical review. Journal of Clinical Psychology, 63, 871-890. https://doi.org/10.1002/jclp.20400.

Cioffi, D., \& Holloway, J. (1993). Delayed costs of suppressed pain. Journal of Personality and Social Psychology, 64(2), 274-282. https://doi.org/10.1037/0022-3514.64.2.274. 
Cohen, J., Cohen, P., West, S., \& Aiken, L. (2003). Applied multiple regression/correlation analysis for the behavioral sciences (3th ed.). New Jersey: Lawrence Erlbaum Associates.

Costa, J., \& Pinto-Gouveia, J. (2013). Experiential avoidance and self-compassion in chronic pain. Journal of Applied Social Psychology, 43(8), 1578-1591. https://doi.org/10.1111/jasp.12107.

Duarte, J., \& Pinto-Gouveia, J. (2017). Correlates of psychological inflexibility mediate the relation between alexithymic traits and positive emotions. Journal of Contextual Behavioral Science, $\quad$ 6(1), $\quad$ 96-103. https://doi.org/10.1016/j.jcbs.2016.12.002.

Gilbert, P. (1998). What is shame? Some core issues and controversies. In B. Andrews, \& P. Gilbert (Eds.), Shame: Interpersonal behavior, psychopathology, and culture (pp. 3-31). New York: Oxford University Press.

Gilbert, P., McEwan, K., Catarino, F., Baião, R., \& Palmeira, L. (2014). Fears of happiness and compassion in relationship with depression, alexithymia, and attachment security in a depressed sample. British Journal of Clinical Psychology, 53(2), 228-244. https://doi.org/10.1111/bjc.12037.

Gilbert, P., McEwan, K., Gibbons, L., Chotai, S., Duarte, J., \& Matos, M. (2012). Fears of compassion and happiness in relation to alexithymia, mindfulness, and selfcriticism. Psychology and Psychotherapy: Theory, Research and Practice, 85(4), 374-390. https://doi.org/10.1111/ j.2044-8341.2011.02046.x.

Gilbert, P., McEwan, K., Matos, M., \& Rivis, A. (2011). Fears of compassion: Development of three self-report measures. Psychology and Psychotherapy, 84(3), 239-255. https://doi.org/10.1348/147608310X526511. 
Gross, J. J. (1998). The emerging field of emotion regulation: An integrative review. Review of General Psychology, 2, 271-299. https://doi.org/10.1037/10892680.2.3.271

Gross, J. J., \& Levenson, R. W. (1997). Hiding feelings: The acute effects of inhibiting negative and positive emotion. Journal of Abnormal Psychology, 106, 95-103. https://doi.org/10.1037/0021-843X.106.1.95.

Hadlandsmyth, K., White, K. S., Nesin, A. E., \& Greco, L. A. (2013). Proposing an acceptance and commitment therapy intervention to promote improved diabetes management in adolescents: A treatment conceptualization. International Journal of Behavioral Consultation and Therapy, 7(4), 12-15. https://doi.org/10.1037/h0100960.

Hair, J. F., Anderson, R. E., Tatham, R. L., \& Black, W. C. (1998). Multivariate Data Analysis. Prentice-Hall International.

Hayes, S. C., Strosahl, K. D., \& Wilson, K. G. (2012). Acceptance and commitment therapy: The process and practice of mindful change (2nd ed.). The Guilford Press: New York.

Hayes, S. C., Strosahl, K. D., Wilson, K. G., Bissett, R. T., Pistorello, J., Toarmino, D., ... McCurry, S. M. (2004). Measuring experiential avoidance: A preliminary test of a working model. The Psychological Record, 54, 553-578.

Hayes, S. C., Wilson, K. G., Gifford, E. V., Follette, V. M., \& Strosahl, K. (1996). Experimental avoidance and behavioral disorders: A functional dimensional approach to diagnosis and treatment. Journal of Consulting and Clinical Psychology, 64(6), 1152-1168. https://doi.org/10.1037/0022-006X.64.6.1152.

Hermanto, N., Zuroff, D. C., Kopala-Sibley, D. C., Kelly, A. C., Matos, M., Gilbert, P., \& Koestner, R. (2016). Ability to receive compassion from others buffers the 
depressogenic effect of self-criticism: A cross-cultural multi-study analysis. Personality and Individual Differences, 98, 324-332. https://doi.org/10.1016/j.paid.2016.04.055.

Hooper, D., Coughlan, J., \& Mullen, M. R. (2008). Structural equation modelling: Guidelines for determining model fit. The Electronic Journal of Business Research Methods, 6(1), 53-60.

Hu, L., \& Bentler, P. M. (1999). Cutoff criteria for fit indexes in covariance structure analysis: Conventional criteria versus new alternatives. Structural Equation Modeling: $\quad$ A $\quad$ Multidisciplinary Journal, $\quad 6(1), \quad$ 1-55. https://doi.org/10.1080/10705519909540118.

Keles, H., Ekici, A., Ekici, M., Bulcun, E., \& Altinkaya, V. (2007). Effect of chronic diseases and associated psychological distress on health-related quality of life. Internal Medicine Journal, 37(1), 6-11. https://doi.org/10.1111/j.14455994.2006.01215.x.

Kellett, S., \& Gilbert, P. (2001). Acne: A biopsychosocial and evolutionary perspective with a focus on shame. British Journal of Health Psychology, 6, 1-24. https://doi.org/10.1348/135910701169025.

Kim, S., Thibodeau, R., \& Jorgensen, R. S. (2011). Shame, guilt, and depressive symptoms: A meta-analytic review. Psychological Bulletin, 137(1), 68-96. https://doi.org/10.1037/a0021466.

Kline, P. (2000). The handbook of psychological testing (2nd ed.). (pp. 13). London: Routledge.

Kline, R. B. (2005). Principles and practice of structural equation modeling. New York: The Guilford Press. 
Maslow, G. R., Haydon, A., McRee, A. L., Ford, C. A. \& Halpern, C. T. (2011). Growing up with a chronic illness: Social success, educational/vocational distress. Journal of Adolescent Health, 49(2), 206-212. https://doi.org/10.1016/j.jadohealth.2010.12.001.

Miron, L. R., Seligowski, A. V., Boykin, D. M., \& Orcutt, H. K. (2016). The potential indirect effect of childhood abuse on posttrauma pathology through selfcompassion and fear of self-compassion. Mindfulness, 7(3), 596-605. https://doi.org/10.1007/s12671-016-0493-0.

Pinto-Gouveia, J., Gregório, S., Dinis, A., \& Xavier, A. (2012). Experiential avoidance in clinical and nonclinical samples. International Journal of Psychology and Psychological Therapy, 12(2), 139-156.

Ruiz, F. J. (2010). A review of acceptance and commitment therapy (ACT) empirical evidence: Correlational, experimental psychopathology, componente and outcome studies. International Journal of Psychology and Psychological Therapy, 10(1), 125-162. https://doi.org/10.1080/028457199439937.

Schumacker, R. E., \& Lomax, R. G. (2004). A beginner's guide to structural equation modeling (2nd ed.). Mahwah, NJ: Lawrence Erlbaum Associates.

Segal, Z. V., Williams, J. M. G., \& Teasdale, J. D. (2002). Mindfulness-based cognitive therapy for depression: A new approach to preventing relapse. New York, NY: Guilford Press.

Simões, C. D. \& Pinto-Gouveia, J. (2012). Medo da Compaixão: Estudo das propriedades psicométricas da Fears of Compassion Scales (FCS) e da sua relação com medidas de Vergonha, Compaixão e Psicopatologia [Fear of compassion: Psychometrics properties of Fears of Compassion Scales (FCS) and 
its relationships with shame, compassion and psychopathology]. Retrieved from https://estudogeral.sib.uc.pt/handle/10316/23280.

Sprecher, S., \& Hendrick, S. S. (2004). Sprecher and Hendrick self-disclosure in intimate relationships self-disclosure in intimate relationships: Associations with individual and relationship characteristics over time. Journal of Social and $\begin{array}{lll}\text { Clinical } & \text { Psychology, }\end{array}$ https://doi.org/10.1521/jscp.23.6.857.54803.

Tangney, J. P., \& Dearing, R. (2002). Shame and guilt in interpersonal relationships. New York: Guilford Press.

Tangney, J., \& Fischer, K. (1995). Self-conscious emotions: The psychology of shame, guilt, embarrassment, and pride. New York, NY: The Guilford Press.

Taylor, R. (2006). Cognitive behavioral therapy for chronic illness and disability (1st ed.). New York: Springer.

The WHOQOL Group (1998). The World Health Organization Quality of Life Assessment (WHOQOL): Development and general psychometric properties. Social Science \& Medicine, 46, 1569-1585. https://doi.org/10.1016/S02779536(98)00009-4.

Trindade, I. A., Ferreira, C., \& Pinto-Gouveia, J. (2016). Inflammatory bowel disease: The harmful mechanism of experiential avoidance for patients' quality of life. Journal of Health Psychology, 21(12), 2882-2892. https://doi.org/10.1177/1359105315587142.

Trindade, I. A., Ferreira, C., \& Pinto-Gouveia, J. (2017a). Chronic illness-related shame: Development of a new scale and novel approach for IBD patients' depressive symptomatology. Clinical Psychology \& Psychotherapy, 24(1), 255-263. https://doi.org/10.1002/cpp.2035. 
Trindade, I. A., Ferreira, C., \& Pinto-Gouveia, J. (2017b). Shame and emotion regulation in inflammatory bowel disease: Effects on psychosocial functioning. Journal of Health Psychology. https://doi.org/10.1177/1359105317718925.

Wegner, D.M., Schneider, D. J., Carter, S. R., \&White, T. L. (1987). Paradoxical effects of thought suppression. Journal of Personality and Social Psychology, 53(1), 513. https://doi.org/10.1037/0022-3514.53.1.5. 
Table 1. List of chronic illnesses presented by participants $(N=115)$

\begin{tabular}{|c|c|c|}
\hline & $n$ & $\%$ \\
\hline Asthma & 26 & 22.6 \\
\hline Crohn's disease & 11 & 9.6 \\
\hline Psoriasis & 11 & 9.6 \\
\hline Celiac disease & 9 & 7.8 \\
\hline Epilepsy & 9 & 7.83 \\
\hline Endometriosis & 6 & 5.22 \\
\hline Endometriosis & 6 & 5.22 \\
\hline Type 1 diabetes & 6 & 5.22 \\
\hline Ulcerative colitis & 6 & 5.22 \\
\hline Multiple sclerosis & 4 & 3.48 \\
\hline Sinusitis & 4 & 3.48 \\
\hline Eczema & 3 & 2.61 \\
\hline Hypothyroidism & 3 & 2.61 \\
\hline Lupus & 3 & 2.61 \\
\hline Other allergies & 3 & 2.61 \\
\hline Polycystic ovarian syndrome & 2 & 1.74 \\
\hline Sickle cell anemia & 2 & 1.74 \\
\hline Asthmatic bronchitis & 1 & 0.87 \\
\hline Atopic dermatitis & 1 & 0.87 \\
\hline Cardiac arrhythmia & 1 & 0.87 \\
\hline Chronic gastritis & 1 & 0.87 \\
\hline Chronic kidney disease & 1 & 0.87 \\
\hline Chronic kidney disease & 1 & 0.87 \\
\hline Hydrocephalus & 1 & 0.87 \\
\hline Irritable bowel syndrome & 1 & 0.87 \\
\hline Lordosis & 1 & 0.87 \\
\hline Muscular dystrophy & 1 & 0.87 \\
\hline Phenylketonuria & 1 & 0.87 \\
\hline Plantar hyperhidrosis & 1 & 0.87 \\
\hline Rheumatism & 1 & 0.87 \\
\hline Sjogren's syndrome & 1 & 0.87 \\
\hline Spina bifida & 1 & 0.87 \\
\hline Vertiginous syndrome & 1 & 0.87 \\
\hline
\end{tabular}

Note. Some participants ( $15 \%$ of the sample) presented more than one diagnosed chronic health condition. 


\section{Table 2}

Means (M), Standard Deviations (SD), Cronbach's alphas $(\alpha)$ and intercorrelation scores of the study variables $(N=115)$

\begin{tabular}{|c|c|c|c|c|c|c|c|c|c|}
\hline & $M$ & $S D$ & $S k$ & $K u$ & $\alpha$ & 1 & 2 & 3 & 4 \\
\hline $\begin{array}{l}\text { 1. Chronic ilness-related } \\
\text { shame }\end{array}$ & 6.58 & 6.82 & 1.06 & 0.40 & 0.93 & - & & & \\
\hline $\begin{array}{l}\text { 2. Fear of compassion from } \\
\text { others }\end{array}$ & 18.85 & 11.46 & 0.61 & -0.16 & 0.92 & $0.54 * * *$ & - & & \\
\hline 3. Experiential avoidance & 24.64 & 8.96 & 0.37 & -0.52 & 0.91 & $0.42 * * *$ & $0.51 * * *$ & - & \\
\hline 4. Social Relationships & 59.57 & 22.52 & -0.25 & -0.54 & 0.76 & $-0.39 * * *$ & $-0.54 * * *$ & $-0.46^{* * *}$ & - \\
\hline 8. Psychological Health & 59.56 & 15.89 & -0.39 & 0.08 & 0.79 & $-0.39 * * *$ & $-0.51 * * *$ & $-0.63 * * *$ & $0.54 * * *$ \\
\hline
\end{tabular}

Note: ${ }^{* * *} p<0.001$ 
Figure 1. Final path model $(N=115)$

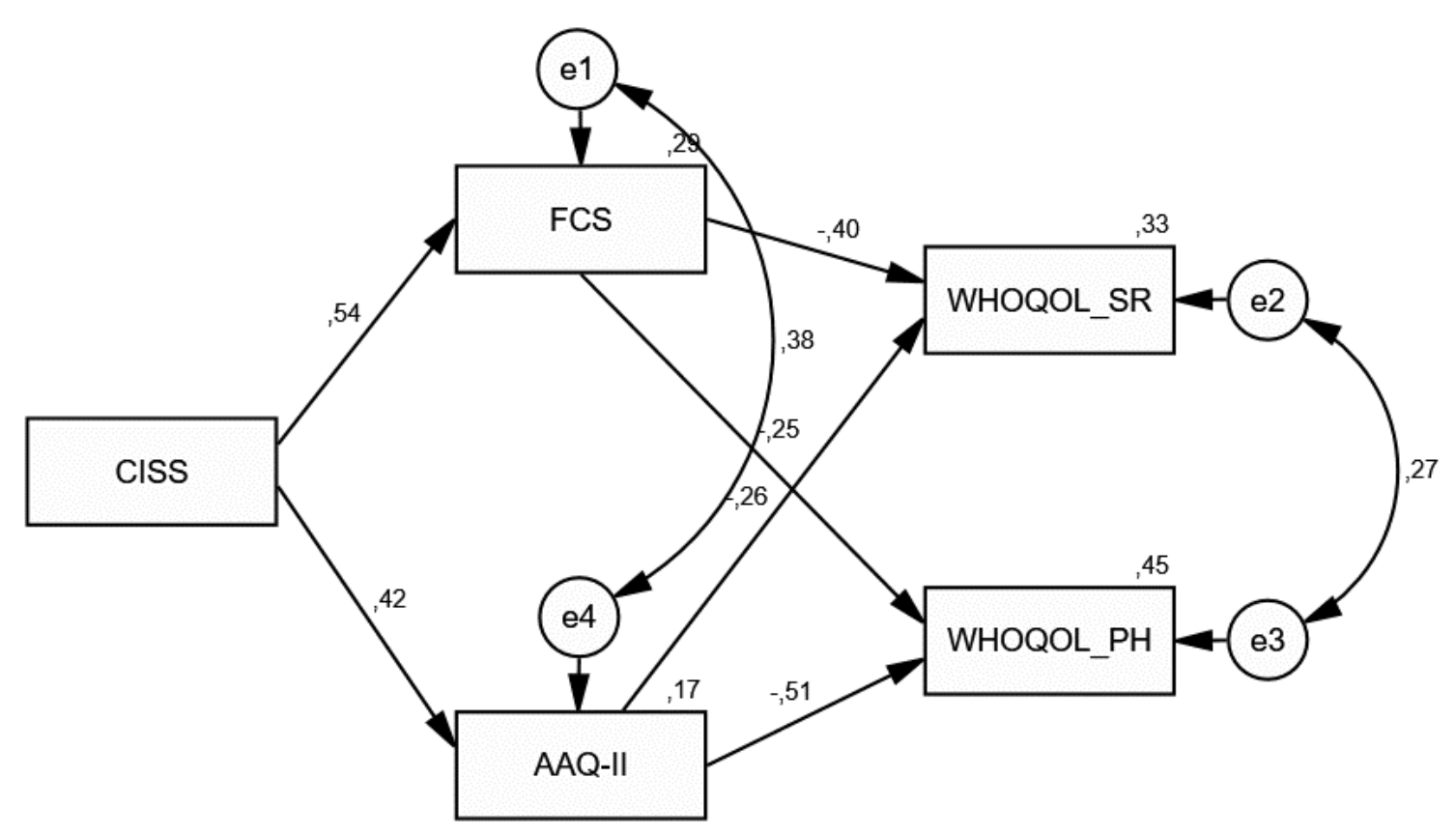

Note. All paths are significant at the $p<0.01$ level. 